\title{
Severe acute respiratory syndrome coronavirus 2 in pregnant women: an observational study
}

\author{
Suyajna Joshi D.*, Vijayalakshmi G., Kavya N., Rai Rajeswari, Ruksar Banu, Jayasakthi
}

Department of Obstetrics and Gynaecology, District Hospital, Bellary, Karnataka, India

Received: 16 October 2020

Accepted: 31 October 2020

\section{*Correspondence:}

Dr. Suyanja Joshi D.,

E-mail: suyajnajoshi@gmail.com

Copyright: (C) the author(s), publisher and licensee Medip Academy. This is an open-access article distributed under the terms of the Creative Commons Attribution Non-Commercial License, which permits unrestricted non-commercial use, distribution, and reproduction in any medium, provided the original work is properly cited.

\begin{abstract}
Background: Severe acute respiratory syndrome coronavirus 2 (SARS-CoV-2) is an emergency health delinquent, with increase in cases worldwide. Pregnant women with COVID-19 positive status are also on rise and reported complications that occur to them during pregnancy, delivery and puerperium accentuates the need for superior care.

Methods: This is a prospective cross sectional observational study of 133 pregnant COVID-19 positive patients delivered at District Hospital, Bellary, Karnataka during the period June 2020 to September 2020.

Results: In the present study $87.9 \%$ were in age 20 to 30 years. $96.3 \%$ patients belong to lower socio-economic status. $4.5 \%$ patients had mild anaemia, $11.2 \%$ had moderate anaemia and $4.5 \%$ had severe anaemia. Non-severe pre-eclampsia was present in $11.2 \%$ of the patients, severe pre-eclampsia in $12 \%$ and $0.7 \%$ had gestational hypertension. Mode of delivery was $17.4 \%$ Full term normal delivery (FTND), 9\% Full term vaginal delivery (FTVD), emergency Lower segment caesarean section (LSCS) in $67.7 \%$ cases and preterm delivery was seen in $4.5 \%$ of the cases. Elevated levels of D-dimer were found in $9.7 \%$ of the cases. One maternal death was reported in the study due to COVID-19 pneumonia. Conclusions: This study evaluates the obstetric and clinical outcome in COVID-19 positive patients who are in labor. Although our conclusions are limited, the findings obtained are important for understanding the clinical parameters, obstetric parameters and perinatal outcome.
\end{abstract}

Keywords: SARS-CoV-2, COVID-19, Coronavirus, Pneumonia, Pandemic, Pregnant women

\section{INTRODUCTION}

Severe acute respiratory syndrome coronavirus 2 (SARS$\mathrm{CoV}-2$ ) as it is now called, is quickly disseminating from its origin in Wuhan City of Hubei Province of China to the rest of the world. ${ }^{1}$ SARS-CoV-2 are enveloped positive sense ribonucleic acid (RNA) viruses with spike like projections on its surface giving it a crown like appearance hence the name coronavirus. ${ }^{2}$ There have been two events in the past two decades, where there has been a crossover of animal beta corona viruses to humans which has given rise to severe disease. The first such event was in 20022003, when a new coronavirus which originated in bats crossed over to humans via palm civet cats in the Guangdong province of China. Again in 2012, the Middle East respiratory syndrome coronavirus (MERS-CoV), also of bat origin, emerged in Saudi Arabia with dromedary camels as the intermediate host. ${ }^{3}$

In December 2019, an increased number of patients in Wuhan, capital city of Hubei province started presenting to local hospitals with severe pneumonia of unknown cause. Many of the initial cases had a common exposure to the Huanan wholesale seafood market that also traded live animals. On December 31st 2019, China alerted the outbreak to the World Health Organization (WHO) and on 1st January the Huanan sea food market was closed. On 7 th January the virus was identified as a coronavirus. All ages are susceptible. Infection spreads through droplets produced during coughing and sneezing by patients but also can occur from asymptomatic people. ${ }^{4}$ Infection is acquired either by inhalation of these droplets or touching 
surfaces tainted by them. The incubation period varies from 2 to 14 days. Studies have identified Angiotensin receptor 2 (ACE2) as the receptor through which the virus enters the respiratory mucosa. ${ }^{5}$ The clinical features of Coronavirus-2019 (COVID-19) are diverse, vacillating from asymptomatic state to acute respiratory distress syndrome and multi organ dysfunction. The common ones include fever, cough, sore throat, headache, fatigue, myalgia and breathlessness. There by being undifferentiated from other respiratory infections. In few patients due to various reasons, by the end of first week the disease can progress to pneumonia, respiratory failure and death. This is due to excessive rise in inflammatory cytokines. Diagnosis is by specific molecular tests on respiratory samples. As per present data, transplacental transmission from pregnant women to their foetus has not been described. Nonetheless, neonatal disease due to postnatal transmission is described. ${ }^{6}$ Previous smaller coronavirus outbreaks (i.e., Severe acute respiratory syndrome (SARS) and Middle East respiratory syndrome (MERS) have associated infection in pregnancy with more serious illness and preterm birth, although information has been primarily from small observational studies and case series. ${ }^{7}$ Similar to nonpregnant patients, the predominant features of SARS-CoV-2 infection in pregnancy are fever, cough, dyspnoea and shortness of breath.

Till date, clinical data whatever is available on pregnant women with SARS-CoV-2 on literature search are very limited. Therefore, this cross-sectional observational study conducted by us is aimed to appraise the clinical features and outcomes of pregnant women with SARS-CoV-2 pneumonia.

\section{METHODS}

This was a prospective observational study conducted in District Hospital, Ballari, Karnataka. All pregnant women who were tested positive for COVID-19, referred from primary health centres, community health centres and private hospitals were included in the study. Their clinical profile and obstetric profile were documented. Verbal and written consent was taken from all the cases before including them in the study. The clinical and outcome data from June 2020 and September 2020 was compiled and analysed. For the purpose of our study, a laboratoryconfirmed case of COVID-19 was defined as a positive result by quantitative reverse transcriptase polymerase chain reaction (qRT-PCR) assay of maternal pharyngeal swab specimens. A total of 133 patients were included in this study and their data was compiled and analysed in detail.

\section{Parameters for assessment}

Obstetrical behaviour and clinical profile of 133 pregnant COVID-19 positive patients were evaluated. Obstetrical behaviour of 133 women during labour, delivery and postpartum period till discharge was highlighted. General physical and detailed systemic examination of all the patients was conducted in a systematic fashion.

All the cases in whom labour was induced, the indication for induction and method utilised were noted. Duration of labour and mode of delivery was recorded. Details of all the babies born were documented along with their COVID-19 status. The mother and baby were followed up in hospital till discharge and their morbidity, mortality was noted if any.

Complete blood count, Human immunodeficiency virus (HIV), Hepatitis B surface antigen (HbsAg), blood grouping and Rhesus (Rh) typing, Ultrasonography (USG), blood urea, serum uric acid, fundoscopy in Pregnancy induced hypertension (PIH) and eclampsia cases, coagulation profile, C-reactive protein (CRP), Lactate dehydrogenase (LDH), D-dimer, serum ferritin, serum electrolytes, Lung function test (LFT), Renal function test (RFT) were included, Electrocardiography (ECG) done, radiological investigations chest X-ray were done and their reports noted.

\section{Statistical analysis}

Data entry and statistical analysis were performed with the help of Statistical package for social sciences (SPSS) version 21.0, while categorical variables are presented as number and percentages.

\section{RESULTS}

Demographics, baseline characteristics, laboratory findings, comorbidities and clinical/obstetric outcomes of all the COVID positive pregnant women were analysed and tabulated as given below in the Tables 1-4.

Table 1: Clinical and obstetric profile of cases.

\begin{tabular}{|llll|}
\hline Characteristics & & Frequency $(\mathrm{n}=\mathbf{1 3 3})$ & \% \\
\hline \multirow{3}{*}{ Age (in years) } & $<20$ & 3 & 2.20 \\
\cline { 2 - 4 } & $20-30$ & 117 & 87.90 \\
\cline { 2 - 4 } Socio-economic status* & $>30$ & 13 & 9.90 \\
& Lower class & 128 & 96.30 \\
\cline { 2 - 4 } & Upper middle class & 5 & 3.70 \\
\hline \multirow{3}{*}{ Gestational age } & Preterm & 27 & 30.30 \\
\cline { 2 - 4 } & Early term & 53 & 39.80 \\
\cline { 2 - 4 } & Full term & 52 & 0.70 \\
\cline { 2 - 4 } & Late term & 1 & 0.70 \\
\hline
\end{tabular}

Continued. 


\begin{tabular}{|llll|}
\hline Characteristics & & Frequency $(\mathrm{n}=\mathbf{1 3 3})$ & \% \\
\hline \multirow{5}{*}{ Gravida } & Gravida 1 & 39 & 29.50 \\
\cline { 2 - 4 } & Gravida 2 & 64 & 48.10 \\
\cline { 2 - 4 } & Gravida 3 & 20 & 15 \\
\cline { 2 - 4 } Parity & Gravida 4 & 3 & 2.20 \\
\cline { 2 - 4 } & Gravida 5 & 1 & 0.70 \\
\cline { 2 - 4 } & Gravida 6 & 6 & 4.50 \\
\hline \multirow{5}{*}{ COVID-19 symptoms } & Parity 0 & 68 & 51.10 \\
\cline { 2 - 4 } & Parity 1 & 20 & 15.10 \\
\cline { 2 - 4 } & Parity 2 & 2 & 1.50 \\
\cline { 2 - 4 } & Parity 3 & 43 & 32.30 \\
\cline { 2 - 4 } & Fatigue & 53 & 53 \\
\cline { 2 - 4 } & Cough & 26 & 19.50 \\
\cline { 2 - 4 } & Diarrhoea & 10 & 7.50 \\
\cline { 2 - 4 } & Anosmia & 1 & 0.70 \\
\cline { 2 - 4 } & Sore throat & 4 & 3 \\
\cline { 2 - 4 } & Asymptomatic & 39 & 29.30 \\
\hline
\end{tabular}

*Modified kuppuswamy's classifications

Table 2: Co-morbidities and modes of delivery among study subjects.

\begin{tabular}{|c|c|c|c|}
\hline Characteristics & & Frequency & $\%$ \\
\hline \multirow{4}{*}{ Hypertensive disorders } & Gestational hypertension & 1 & 0.70 \\
\hline & Mild preeclampsia & 15 & 11.2 \\
\hline & Severe preeclampsia & 12 & 12 \\
\hline & Imminent eclampsia & 2 & 1.50 \\
\hline \multirow{3}{*}{ Anaemia (n=27) } & Mild anaemia & 6 & 4.50 \\
\hline & Moderate anaemia & 15 & 11.2 \\
\hline & Severe anaemia & 6 & 4.50 \\
\hline \multirow{12}{*}{ Others $(n=24)$} & Hypothyroidism & 1 & 0.70 \\
\hline & HELLP syndrome & 5 & 3.70 \\
\hline & Thrombocytopenia & 3 & 2.20 \\
\hline & HbsAg & 1 & 0.70 \\
\hline & Bicornuate uterus & 1 & 1.50 \\
\hline & Gestational diabetes Mellitus & 2 & 1.50 \\
\hline & Intra uterine death & 4 & 3 \\
\hline & Abruption placentae & 2 & 1.50 \\
\hline & Placentae previa & 2 & 1.50 \\
\hline & APLA syndrome & 1 & 0.70 \\
\hline & Retained placenta & 1 & 0.70 \\
\hline & Overt diabetes & 1 & 0.70 \\
\hline
\end{tabular}

Table 3: Distribution of patients based on laboratory findings of COVID-19 and treatment.

\begin{tabular}{|llll|}
\hline \multirow{4}{*}{ Laboratory parameters } & & Frequency & $\%$ \\
\cline { 2 - 4 } & D-Dimer (>500) & 13 & 9.7 \\
\cline { 2 - 4 } & CRP & Negative & 73.70 \\
\cline { 2 - 4 } Treatment & Radiologic findings & 15 & 26.30 \\
\cline { 2 - 4 } & Antibiotic therapy & 133 & 11.20 \\
\cline { 2 - 4 } & Treatment with remedisvir & 15 & 100 \\
\cline { 2 - 4 } & Corticosteroids therapy & 15 & 11.20 \\
\cline { 2 - 4 } & ICU admission & 1 & 11.20 \\
\hline
\end{tabular}


Table 4: Pregnancy outcomes and neonatal outcomes among study subjects.

\begin{tabular}{|c|c|c|c|}
\hline Outcome & & Frequency & $\%$ \\
\hline \multirow{6}{*}{ Mode of delivery } & EMERGENCY LSCS & 90 & 67.70 \\
\hline & FTND & 23 & 17.40 \\
\hline & FTVD & 12 & 9 \\
\hline & PTVD & 6 & 4.50 \\
\hline & VBAC & 1 & 0.70 \\
\hline & Assisted breech delivery & 1 & 0.7 \\
\hline \multirow{11}{*}{$\begin{array}{l}\text { Indication in caesarean section } \\
(\mathbf{n}=90)\end{array}$} & Breech presentation & 4 & 4.40 \\
\hline & Fetal distress & 13 & 14.40 \\
\hline & Previous 1 LSCS & 41 & 45.70 \\
\hline & CPD & 11 & 12.20 \\
\hline & Previous 2 LSCS & 3 & 3.30 \\
\hline & Second stage arrest & 1 & 1.10 \\
\hline & Oligohydramnios & 6 & 6.80 \\
\hline & Bad obstetrics history & 2 & 2.20 \\
\hline & Precious pregnancy & 3 & 3.30 \\
\hline & Transverse lie & 2 & 2.20 \\
\hline & Twin gestation & 4 & 4.40 \\
\hline \multirow{2}{*}{ Intrapartum complications $(\mathrm{n}=3)$} & Retained placenta & 1 & 0.70 \\
\hline & Ruptured uterus & 2 & 1.50 \\
\hline \multirow{5}{*}{ Post-operative complications } & Postpartum haemorrhage & 7 & 5.20 \\
\hline & Secondary PPH & 1 & 0.70 \\
\hline & PRES syndrome & 1 & 0.70 \\
\hline & Psychosis & 1 & 0.70 \\
\hline & DIC & 2 & 1.50 \\
\hline \multirow{2}{*}{ Birth weight of baby $(n=137)$} & $<2.5 \mathrm{kgs}$ & 39 & 28.50 \\
\hline & $\geq 2.5 \mathrm{kgs}$ & 98 & 71.50 \\
\hline \multirow{12}{*}{ Perinatal outcome } & Baby NICU admission & 65 & 47.40 \\
\hline & COVID 19 positive babies & 7 & 5.10 \\
\hline & Respiratory distress syndrome & 8 & 5.80 \\
\hline & Meconium aspiration syndrome & 12 & 8.70 \\
\hline & $\begin{array}{l}\text { Other causes of Respiratory distress } \\
\text { syndrome }\end{array}$ & 2 & 1.40 \\
\hline & Hypoxic ischemic encephalopathy & 9 & 6.50 \\
\hline & Sepsis & 1 & 0.70 \\
\hline & Jaundice & 11 & 8 \\
\hline & Hypoglycaemia & 1 & 0.70 \\
\hline & Dehydration fever & 5 & 3.60 \\
\hline & Low birth weight with prematurity & 5 & 3.60 \\
\hline & IDM & 1 & 0.70 \\
\hline Maternal mortality & Maternal mortality & 1 & 0.70 \\
\hline Perinatal mortality & Perinatal mortality & 2 & 1.50 \\
\hline
\end{tabular}

LSCS : lower segment caesarean section, FTNVD: full term normal vaginal delivery, VBAC: vaginal birth after caesarean section, PPH: post-partum haemorrhage, NICU: neonatal intensive care unit, IDM : infant of diabetic mother, PRES: posterior reversible encephalopathy syndrome, DIC: disseminated intravascular coagulation, CPD: cephalopelvic disproportion.

Table 5: Most common symptoms observed.

\begin{tabular}{|lclll|}
\hline Common symptoms & Dashrath et al ${ }^{10}(\%)$ & Yu et al ${ }^{11}(\%)$ & Chen et al $^{\mathbf{1 2}}(\%)$ & Elshafeey et al ${ }^{13}(\%)$ \\
\hline Fever & 84 & 86 & 75 & 67.3 \\
\hline Cough & 28 & 14 & 73 & 65.7 \\
\hline Dyspnea & 18 & 14 & 7 & 7.3 \\
\hline Diarrhea & - & 14 & 7 & 7.3 \\
\hline Lymphopenia & 38 & - & 44 & 14 \\
\hline Leucocytosis & 22 & - & - & - \\
\hline others & - & - & 6 & $<5$ \\
\hline
\end{tabular}


A total of 133 cases $(\mathrm{N})$ were included in the study, and mean age of the pregnant women in the study was 24.4 years. There was one maternal death reported in our study and which was due to COVID-19 pneumonia.

\section{DISCUSSION}

Clinical data whatever is available on pregnant women with SARS-CoV-2 on literature search are very limited. This is a novel condition and its effect on pregnancy is not fully known. Impact of this disease on pregnant women and what effect, if any, this disease would have on the foetus is still not fully understood. Currently no definitive evidence-based guidelines specific to pregnant women regarding the evaluation or management of COVID-19 is available in the literature.

When compared to the present study, where mean age is 24.4years, Yan et al and Wong et al in their study reported the mean age of incidence as 30.8 years and 35.5 years. ${ }^{8,9}$ Early marriage and poor acceptance of modern family planning methods could have been responsible for the mean age of 24.4 years in our study. Most common clinical symptoms observed in various studies as compared to our study is as tabulated below (table 5).

In a study conducted by Yan et al, $55.2 \%$ patients were nulliparous, $44.8 \%$ multiparous when compared to $51.1 \%$ of nulliparous women in our study. ${ }^{8}$

In our study non-severe pre-eclampsia, severe preeclampsia, gestational hypertension and imminent eclampsia was seen in $11.2 \%, 12 \%, 0.7 \%$ and $1.5 \%$ of the cases respectively. Yan et al in their study reported hypertensive disorders and preeclampsia in $4.3 \%$ and $3.4 \%$ cases respectively. ${ }^{8}$ Similarly, Ali et al in there study reported pre-eclampsia, hypertension, mild anaemia, moderate anaemia and severe anaemia in $3.3 \%, 2.2 \%$ $4.5 \%, 11.2 \%$ and $4.5 \%$ of the cases respectively. ${ }^{14}$

Yan et al in their study reported full term normal delivery, full term vaginal delivery, emergency caesarean section, post term vaginal delivery and vaginal delivery after caesarean section in $17.4 \%, 9 \%, 67.7 \%, 4.5 \%$ and $0.7 \%$ respectively. ${ }^{8}$

In a study by Yan et al $85.9 \%$ underwent LSCS and remaining had vaginal delivery. ${ }^{8}$ LSCS was indicated for COVID-19 pneumonia, previous cesarean delivery, fetal distress and failure to progress in $38.8 \%, 18.8 \%, 10.6 \%$ and $38.8 \%$ respectively. Similarly Ali et al in their study, reported most common indication for caesarean section as pregnant women infected with COVID-19 pneumonia along with other indications being foetal distress in $18.5 \%$, prolonged rupture of membrane in $7.4 \%$, history of stillbirth in $1.2 \%$, stillbirth in $1.2 \%$, incomplete rotation of the head in $1.2 \%$, chorioamnionitis and meconium stained amniotic fluid in $2.4 \%$ and preeclampsia in $2.4 \%$ of the cases. $^{14}$
Intraoperative complications in this study was retained placenta constituting $0.7 \%$ and ruptured uterus $1.5 \%$ which was secondary to scar rupture, hence could not be attributed directly to COVID-19 infection.

In the present study, majority of the babies born had a birth weight of $>2.5 \mathrm{kgs}(73.7 \%)$. Ali et al in their study reported neonate's birth weight ranging from 1.5 to $3.8 \mathrm{kgs}$ out of which eleven had low birth weight, two were small for gestational age (SGA), and one was large for gestational age (LGA). ${ }^{14}$

Among seven COVID-19 positive new-born's, nasopharyngeal and oropharyngeal swabs were taken on day 2 of their birth. Four babies were delivered by caesarean section and remaining 3 babies were delivered vaginally.

\section{CONCLUSION}

As this is a new infection the evidence is changing on a daily basis. It's true impact on foetal and maternal wellbeing is still not very well understood. Our aim is to be UpToDate with the treatment guidelines of COVID-19 infection amongst pregnant population and to imply measures to stem the spread of the infection. we are faced with the vision of having to co-exist with this virus until an effective treatment option is found. We have a social responsibility towards the pregnant women and must plan on how we can begin to re-establish our gynaecology and obstetrics services and to ensure all women receive the necessary care they need in these difficult and unusual times. We are hoping that the data from this observational study conducted by us is successful in appraising the clinical features and outcomes of pregnant women with SARS-CoV-2 pneumonia.

\section{ACKNOWLEDGMENTS}

I would like to express my sincere gratitude to Dr Basareddy, District surgeon, District hospital Ballari for his insightful comments and encouragement.

\section{Funding: No funding sources \\ Conflict of interest: None declared}

Ethical approval: The study was approved by the Institutional Ethics Committee

\section{REFERENCES}

1. Wang C, Horby PW, Hayden FG, Gao GF. A novel coronavirus outbreak of global health concern. The Lancet. 2020;395(10223):470-3.

2. Richman DD, Whitley RJ, Hayden FG. Clinical Virology, 4th ed. Washington: ASM Press. 2016.

3. Memish ZA, Perlman S, Van Kerkhove MD, Zumla A. Middle East respiratory syndrome. The Lancet. 2020;395(10229):1063-77. 
4. Rothe C, Schunk M, Sothmann P. Transmission of 2019- nCoV infection from an asymptomatic contact in Germany. N Engl J Med. 2020;382:970-1.

5. Cheng ZJ, Shan J. 2019 novel coronavirus: where we are and what we know. Infection. 2020;48:155-63.

6. Chen H, Guo J, Wang C. Clinical characteristics and intrauter- ine vertical transmission potential of COVID-19 infection in nine pregnant women: a retrospective review of medical records. Lancet. 2020;395(10226):809-15.

7. Wong SF, Chow KM, Leung TN. Pregnancy and perinatal outcomes of women with severe acute respiratory syndrome. Am J Obstet Gynecol. 2004;191:292-7.

8. Yan J, Guo J, Fan C, Juan J, Yu X, Li J, et al. Coronavirus disease 2019 (COVID-19) in pregnant women: A report based on 116 cases. Am J Obstetr Gynecol. 2020;223:111.e1-14.

9. Wong SF, Chow KM, Leung TN, Ng WF, Ng TK, Shek CC, et al. Pregnancy and perinatal outcomes of women with severe acute respiratory syndrome. Am J Obstetr Gynecol. 2004;191(1):292-7.

10. Dashraath P, Wong JLJ, Lim MXK. Coronavirus disease 2019 (COVID-19) pandemic and pregnancy. Am J Obstet Gynecol. 2020:S0002-9378(20)30343-4.
11. Yu N, Li W, Kang Q. Clinical features and obstetric and neonatal outcomes of pregnant patients with COVID-19 in Wuhan, China: A retrospective, singleCentre, descriptive study. Lancet Infect Dis. 2020;20:559-64.

12. Chen L, Li Q, Zheng D. Clinical characteristics of pregnant women with Covid-19 in Wuhan, China. N Engl J Med. 2020;NEJMc2009226.

13. Elshafeey F, Magdi R, Hindi N. A systematic scoping review of COVID-19 during pregnancy and childbirth. Int J Gynaecol Obstet. 2020.

14. Ashraf MA, Keshavarz P, Hosseinpour P, Erfani A, Roshanshad A, Pourdast A, et al. Coronavirus disease 2019 (COVID-19): a systematic review of pregnancy and the possibility of vertical transmission. J Reprod Infertility. 2020;21(3):157.

Cite this article as: Suyajna JD, Vijayalakshmi G, Kavya N, Rajeswari R, Banu R, Jayasakthi. Severe acute respiratory syndrome coronavirus 2 in pregnant women: an observational study. Int J Reprod Contracept Obstet Gynecol 2020;9:4892-7. 